\title{
DESMOID-TYPE FIBROMATOSIS IN THE MALE BREAST MIMICKING CANCER
}

Lilian de Sá Paz Ramos¹,2, Jorge Villanova Biazús', Andréa Pires Souto Damin¹, Sálvia Maria Canguçu da Rocha², Ana Claudia Imbassahy de Sá Bittencourt Câmara e Silva²

1Postgraduate Program In Health Sciences: Obstetrics And Gynecology Of, Universidade Federal do Rio Grande do Sul Porto Alegre (RS), Brazil.

${ }^{2}$ Hospital Aristides Maltez - Salvador (BA), Brazil.

Introduction: Desmoid-type fibromatosis (DTF) is defined as a clonal proliferation of fibroblasts that emerges in soft tissues, with a tendency to infiltrate local tissues and toward local recurrence, but with no potential of distant metastases. The breast is an unusual location, corresponding to approximately $0.2 \%$ of all breast tumors. The literature has few DTF cases described in the male breast. The etiology of the lesion is unclear. Fibromatosis presents as a firm, painless, and mobile mass, which can be fixed to the pectoralis major or the skin. Radiological characteristics are nonspecific. The lesion manifests as a suspicious solid mass with irregular margins, making it difficult to differentiate the lesion from breast cancer on mammography, ultrasound, and magnetic resonance imaging. Immunohistochemistry (IHC) shows positivity for vimentin, ß-catenin, and actin, with negative desmin. Standard treatment consists of resection of the lesion with margins. Objective: To report a rare case of DTF in the male breast. Method: This is the description of the clinical case based on medical records. Result: A 42-year-old man had a nodule in the left breast for 1 year. He had no medical or family history of breast cancer. The patient presented a firm tumor with ill-defined margins, slightly mobile, adhered to the skin, measuring $5 \mathrm{~cm}$, in the left upper inner quadrant during physical examination. Mammography showed asymmetry in the left breast, BI-RADS 4 Core biopsy indicated fibrosis, with segmental resection of the lesion. Histology revealed fibrous infiltrative neoplasm, with an intense collagenic aspect, $3.5 \mathrm{~cm}$, and free margins. IHC was positive for vimentin, actin, and $\bigotimes$-catenin, compatible with DTF. Conclusion: DTF in the male breast is a rare, locally invasive, benign tumor. It presents suspicious clinical and radiological aspects similar to those of breast cancer. The main treatment consists of resection of the lesion with satisfactory margins. 